\title{
Influence of the Structural Characteristics of Amino Acids on Direct Methylation Behaviors by TMAH in Pyrolysis
}

\author{
Sung-Seen Choi and Ji-Eun Ko

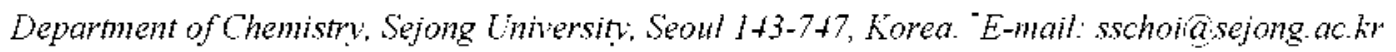 \\ Recerved Hay 13, 2009, Accepted September 7, 2009
}

\begin{abstract}
Direct methy lation behaviors of 20 amino acids with tetramethylammoniun hydroxide (TMAH) were studied under diluted conditions with silica. Amino acid concentration was controlled by dilution with silica $\left(\mathrm{SiO}_{2}\right)$ and the molar ratios of anino acid/silica were $0.20,0.50$, and 2.0. The molar ratios of anino acid/TMAH $(0.51-4.64)$ also varied. It was found that arginine, asparagine, aspartic acid, cysteine, glutamic acid, and glutamine did not generate any directly methylated pyrolysis products, whereas alanine, glycine, isoleucine, leucine, methionine, phenylanaline, valine, and proline generated all the directly methylated pyrolysis products. Tri- and tetra methylated products of lysine consisted of two types. Histidine and threonine hardly generated the partly methylated products. Mono- and dimethylated products of serine, tryptophan, and tyrosine were not observed. Relative intensities of the methylated products varied with the amino acid concentration. TMAH concentration, and pyrolysis temperature. Direct methylation behaviors of amino acids were explained by the structural characteristics of anino acids.
\end{abstract}

Key Words: Amino acids. Direct methỵlation. TMAH. P̧̣-GC/MS. Silica

\section{Introduction}

Analytical pyrolysis is widely utilized for the chenical characterization of complex organic materials of natural origin and pyrolysis-gas chromatography/mass spectrometry ( $\mathrm{Py}-\mathrm{GC} /$ MS) is one of the most widely used analytical tools to characterize recalcitrant macromolecules at the molecular level. ${ }^{1-3}$ Amino acids are important constitutive units or starting components of various organic macromolecules such as proteins and humic substances. The pyrolytic behaviors of common amino acids have been investigated and the principal thermal degradation products have been identified through $\mathrm{Py}-\mathrm{GC} /$ MS. "However, the usefulness of this technique is limited by unexpected secondary reactions of pyrolyzates during the pyrolysis process and difficulty with polar pyrolyzates analyzed by $\mathrm{GC} / \mathrm{MS}$. In order to overcome these limitations. py rolysis in the presence of tetraalkylammonium hydroxide was developed. The most efficient reagent was proven to be tetramethy lammonium hydroxide (TMAH) which is used as a methylating agent. ${ }^{8.11}$ The application of TMAH thermochemoly'sis for the study of proteinaceous materials ${ }^{12-15}$ is important because of the significant amounts of proteinaceous materials found in environmentally and geochemically important samples.

In previous studies. ${ }^{86.17}$ TMAH was used excess for direct methy lation of amino acids. These studies reported that partly methylated products were also generated along with fully methylated ones. The degree of direct methylation related to amino acids and the variation associated with methylated products have not been studied in detail. In this study. amino acids were pyrolyzed in the presence of silica to dilute amino acids. Pyrroly sis behaviors based on amino acid concentration and py rolysis temperature were investigated. Inorganic materials such as $\mathrm{Al}_{2} \mathrm{O}_{3}, \mathrm{SiO}_{2}, \mathrm{CaO} . \mathrm{Na}_{-} \mathrm{CO}_{3}$, and $\mathrm{NaCl}$ affected the formation of pyrolysis products. ${ }^{18}$ The degree of direct methylation and variation of the relative abundances of the methylated products were also investigated. Differences in the direct methylation behavions of amino acids were explained by the structural characteristics of the amino acids.

\section{Experimental}

Phenylalanine, ty rosine. tryptophan. serine, valine. and glycine were purchased from Daejung Chemicals \& Metals Co. (Korea). Argine. aspartic acid, glutanic acid, and proline were purchased from Samchun Pure Chemical Co. (Korea). Alanine, histidine, leucine. glutamine. threonine. and asparagine were purchased from Junsei Chemaical Co. (Japan). Lysine and isoleucine were purchased from Acros Organics (USA). and Cysteine was purchased from Merck Co. (Gemany). Methionine was purchased from Yakuri Pure Chemicals Co. (Japan). Fumed silica was purchased from Merck Co. (Germany). Tetramethylammonium hydroxide (TMAH. 25\% in methanol) was purchased from Lancaster Synthesis Inc. (UK). We used silica after drying it in $150^{\circ} \mathrm{C}$ oven to remove water. Each amino acid was mixed with silica (amino acid $\mathrm{SiO}_{2}=1: 5,1: 2$. and $2: 1$ by the molar ratio) and pelletized. The $0.2 \mu \mathrm{L}$ TMAH in methanol was added to the $0.3 \mathrm{mg}$ mixture sample. After the methanol evaporated, the sample was placed into a quartz tube.

Py rolysis-GC/MS was carried out by using a CDS Py roprobe 1500 heated filament pyrolyzer (Chenical Data System, Oxford. USA) coupled to an Agilient 6890 gas chromatograph equipped with a 5973 mass spectrometer of Agilent Technology Inc. (USA). An HP-5MS (30 $\mathrm{m} \times 0.25 \mathrm{~mm}$ i.d. $0.25 \mu \mathrm{m}$ film thickness colunn, Agilent Technology Inc.) was used. The following analysis conditions were used: py rolysis temperature and time. $700^{\circ} \mathrm{C}$ and $3 \mathrm{sec}$ : GC injector temperature. $250^{\circ} \mathrm{C}$; split matio, $1: 20$ : GC oven temperature progran. $50{ }^{\circ} \mathrm{C}$ (held for $3 \mathrm{~min}$ ) to $250^{\circ} \mathrm{C}$ at $10^{\circ} \mathrm{C} / \mathrm{min}$. carrier gas. helium (flow rate. $1.5 \mathrm{~mL} / \mathrm{min}$ ): the interface temperature of $\mathrm{GC}$ to $\mathrm{MS}, 250^{\circ} \mathrm{C}$. The electron impact ionization (electron energy $70 \mathrm{eV}$ ) was used to ionize the py rolysis products. The 
Table 1. Molar ratios of amino acids and TMAH (anino acid/ TMAH).

\begin{tabular}{llll}
\hline Amino acid/Silica & 0.2 & 0.5 & 2.0 \\
\hline Alanine (Ala) & 1.16 & 2.32 & 4.64 \\
Arginine (Arg) & 0.59 & 1.19 & 2.37 \\
Asparagine (Asn) & 0.78 & 1.57 & 3.13 \\
Aspartic acid (Asp) & 0.78 & 1.55 & 3.11 \\
Cysteine (Cys) & 0.85 & 1.71 & 3.42 \\
Glutamic acid (Glu) & 0.70 & 1.41 & 2.81 \\
Glutamine (Gln) & 0.71 & 1.42 & 2.83 \\
Glycine (Gly) & 1.38 & 2.75 & 5.51 \\
Histidine (His) & 0.64 & 1.28 & 2.57 \\
Isoleucine (Ile) & 0.79 & 1.58 & 3.15 \\
Leucine (Leu) & 0.79 & 1.58 & 3.15 \\
Lysine (Lys) & 0.71 & 1.42 & 2.83 \\
Methionine (Met) & 0.69 & 1.39 & 2.77 \\
Phenylalanine (Phe) & 0.63 & 1.25 & 2.50 \\
Proline (Pro) & 0.90 & 1.80 & 3.59 \\
Serine (Ser) & 0.98 & 1.97 & 3.94 \\
Threonine (Thr) & 0.87 & 1.74 & 3.47 \\
Tryptophan (Trp) & 0.51 & 1.01 & 2.03 \\
Tyrosine (Tyr) & 0.57 & 1.41 & 2.28 \\
Valine (Val) & 0.88 & 1.77 & 3.53 \\
\hline
\end{tabular}

MS source temperature was $230^{\circ} \mathrm{C}$.

The quantitative analysis was performed using an Acme 6000 gas chromatograph of Younglin $\mathrm{Co}$. (Korea) equipped with a flame ionization detector (FID). Nitrogen was used as carrier gas (flow rate $2.0 \mathrm{~mL} / \mathrm{min}$ ). The FID and injector temperatures were set at $250^{\circ} \mathrm{C}$. An HP-5 $(30 \mathrm{~m} \times 0.25 \mathrm{~mm}$ i.d., $0.25 \mu \mathrm{m}$ film thickness column. Agilent technology Inc.) was temperature programmed from $50^{\circ} \mathrm{C}$ (held for $3 \mathrm{~min}$ ) to 250 ${ }^{\circ} \mathrm{C}$ at a rate of $10^{\circ} \mathrm{C} / \mathrm{nin}$. The split ratio was $1: 20$. The sample was py rolyzed at $400,500.700$ and $900^{\circ} \mathrm{C}$

\section{Results and Discussion}

The py rolysis products of the amino acids were identified through $\mathrm{GC} / \mathrm{MS}$. the quantitative analysis was performed with GC-FID. The molar ratios of the amino acids, silica. and TMAH of the samples are summarized in Table 1 . The molar ratios of the amino acid/silica were 0.2 .0 .5 . and 2.0. and those of the amino acid/TMAH were $0.5 \mathrm{l}$ to $5.5 \mathrm{l}$. The direct methylated pyrolysis products are summarized in Table 2 . For arginine, asparagine. aspartic acid. cysteine, glutamic acid. and glutamine. no directly methylated py rolysis products were observed. Gallois and coworkers ${ }^{16}$ reported that arginine, asparagine, and aspartic acid did not generate direct methy lated py roly'sis products but cysteine. glutanic acid. and glutamine produced

Table 2. Directly methylated pyrolysis products of amino acid monomers.

\begin{tabular}{|c|c|c|c|}
\hline Amino acid & Degree of methylation & $n / z$ (chemical formula) & Compound \\
\hline \multirow{3}{*}{ Alanine } & MI & $103\left(\mathrm{C}_{4} \mathrm{H}_{0} \mathrm{NO}_{2}\right)$ & Alanine methyl ester \\
\hline & M2 & $117\left(\mathrm{C}_{4} \mathrm{H}_{1} \mathrm{NO}_{2}\right)$ & N-Methylalanine methyl ester \\
\hline & M3 & $13 \mathrm{l}\left(\mathrm{C}_{6} \mathrm{H}_{1}: \mathrm{NO}_{2}\right)$ & $N, N$-Dimethylalanine methyl ester \\
\hline Arginine & \multicolumn{2}{|l|}{ None } & \\
\hline Asparagine & \multicolumn{2}{|l|}{ None } & \\
\hline Aspartic acid & \multicolumn{2}{|l|}{ None } & \\
\hline Cysteine & \multicolumn{2}{|l|}{ None } & \\
\hline Glutamic acid & \multicolumn{2}{|l|}{ None } & \\
\hline Glutamine & \multicolumn{2}{|l|}{ None } & \\
\hline \multirow[t]{3}{*}{ Glycine } & Ml & $89\left(\mathrm{C}_{3} \mathrm{H}-\mathrm{NO}_{2}\right)$ & Glycine methyl ester \\
\hline & M2 & $103\left(\mathrm{C}_{4} \mathrm{H}_{4} \mathrm{NO}_{2}\right)$ & N-Methylglycine methyl ester \\
\hline & Mi & $117\left(\mathrm{C}_{5} \mathrm{H}_{1} \mathrm{NO}_{2}\right)$ & $N \times$-Dimethylglycine methyl ester \\
\hline Histidine & M4 & $211\left(\mathrm{C}_{11} \mathrm{H}_{1}: \mathrm{N}_{3} \mathrm{O}_{2}\right)$ & $N_{1} X^{\prime \prime}$-Trimethylhistidine methyl ester \\
\hline \multirow[t]{3}{*}{ Isoleucine } & MI & $145\left(\mathrm{C}_{2} \mathrm{H}_{15} \mathrm{NO}_{2}\right)$ & Isoleucine methyl ester \\
\hline & M2 & $159\left(\mathrm{C}_{8} \mathrm{H}_{1}: \mathrm{NO}_{2}\right)$ & N-Methylisoleucine methyl ester \\
\hline & M3 & $173\left(\mathrm{C}_{4} \mathrm{H}_{14} \mathrm{NO}_{2}\right)$ & N, -Dimethylisolencine methyl ester \\
\hline \multirow[t]{3}{*}{ Leucine } & MI & $145\left(\mathrm{C}_{-} \mathrm{H}_{15} \mathrm{NO}_{2}\right)$ & Leucine methyl ester \\
\hline & M2 & $159\left(\mathrm{C}_{8} \mathrm{H}_{1}: \mathrm{NO}_{2}\right)$ & N-Methylleucine methyl ester \\
\hline & M3 & $173\left(\mathrm{C}_{4} \mathrm{H}_{19} \mathrm{NO}_{2}\right)$ & $N, X$-Dimethylleucine methyl ester \\
\hline \multirow[t]{5}{*}{ Lysine } & M3 & $188\left(\mathrm{C}_{9} \mathrm{H}_{20} \mathrm{~N}_{2} \mathrm{O}_{2}\right)$ & $N^{\prime} x^{t}$-Dimethyllycine methỵl ester \\
\hline & $\mathrm{M} 4$ & $202\left(\mathrm{C}_{10} \mathrm{H}_{22} \mathrm{~N}_{2} \mathrm{O}_{2}\right)$ & $\mathrm{N}^{+} \mathrm{N}^{t}$-Trimethyllycine methyl ester \\
\hline & Mi: & $188\left(\mathrm{C}_{4} \mathrm{H}_{20} \mathrm{~N}_{2} \mathrm{O}_{2}\right)$ & No-Dimethyllycine methyl ester \\
\hline & M4: & $202\left(\mathrm{C}_{113} \mathrm{H}_{22} \mathrm{~N}_{2} \mathrm{O}_{2}\right)$ & $\mathrm{N} \mathrm{N}^{\prime} \mathrm{\prime}^{\prime}$-Trimethyllycine methyl ester \\
\hline & M5 & $216\left(\mathrm{C}_{11} \mathrm{H}_{2}+\mathrm{N}_{2} \mathrm{O}_{2}\right)$ & $N_{1} \mathrm{~N}^{\prime \prime} \mathrm{H}^{\prime \prime}$-Tetramethyllycine methyl ester \\
\hline
\end{tabular}


Table 2. Continued.

\begin{tabular}{|c|c|c|c|}
\hline Amilo acid & Degree of methylation & $m / z$ (chemical formula) & Compound \\
\hline \multirow{3}{*}{ Methionine } & MI & $163\left(\mathrm{C}_{n} \mathrm{H}_{13} \mathrm{NO}_{2} \mathrm{~S}\right)$ & Methionine methyl ester \\
\hline & M2 & $177\left(\mathrm{C}_{2} \mathrm{H}_{14} \mathrm{NO}_{2} \mathrm{~S}\right)$ & N-Methylmethionine methyl ester \\
\hline & Mi & $191\left(\mathrm{C}_{8} \mathrm{H}_{1}: \mathrm{NO} \mathrm{S}_{2}\right)$ & $N \mathrm{~N}$-Dimethy lmethionine methyl ester \\
\hline \multirow{3}{*}{ Phenylalanine } & MI & $179\left(\mathrm{C}_{110} \mathrm{H}_{1} \mathrm{NO}_{2}\right)$ & Phenylalanine methyl ester \\
\hline & M2 & $193\left(\mathrm{C}_{11} \mathrm{H}_{15} \mathrm{NO}_{2}\right)$ & N-Methylphenylalanine methyl ester \\
\hline & $\mathrm{Mi}$ & $207\left(\mathrm{C}_{12} \mathrm{H}_{1}: \mathrm{NO}_{2}\right)$ & $N$ N-Dimethylphenylalanine methyl ester \\
\hline \multirow{2}{*}{ Proline } & MI & $129\left(\mathrm{C}_{n} \mathrm{H}_{1} \mathrm{NO}_{2}\right)$ & Proline methyl ester \\
\hline & M2 & $143\left(\mathrm{C}_{2} \mathrm{H}_{1}: \mathrm{NO}_{2}\right)$ & N-Methylproline methyl ester \\
\hline \multirow[t]{2}{*}{ Serine } & M3 & $147\left(\mathrm{C}_{6} \mathrm{H}_{13} \mathrm{NO}_{3}\right)$ & $\mathrm{N}$-Methyy $\mathrm{l}-\mathrm{O}$-methylserine methỵl ester \\
\hline & M4 & $161\left(\mathrm{C}_{2} \mathrm{H}_{1} \mathrm{NO}_{3}\right)$ & $\mathrm{N} X$-Dimethy $\mathrm{l}-\mathrm{O}$-methy lserine methyl ester \\
\hline \multirow{2}{*}{ Threonine } & MI & $133\left(\mathrm{C}_{5} \mathrm{H}_{4} \mathrm{NO}_{3}\right)$ & Threonine methvl ester \\
\hline & M4 & $175\left(\mathrm{C}_{8} \mathrm{H}_{1}: \mathrm{NO}_{3}\right)$ & $N_{1} X$-Dimethy $\mathrm{l}-O$-methylthreonine methyl ester \\
\hline \multirow{2}{*}{ Tryptophan } & Mi & $246\left(\mathrm{C}_{14} \mathrm{H}_{18} \mathrm{~N}_{2} \mathrm{O}_{2}\right)$ & $N, X$-Dimethyltryptophan methyl ester \\
\hline & M4 & $260\left(\mathrm{C}_{15} \mathrm{H}_{20} \mathrm{~N}_{2} \mathrm{O}_{2}\right)$ & $N_{1} x^{\prime}$-Trimethyltryptophan methyl ester \\
\hline \multirow[t]{2}{*}{ Tyrosine } & M3 & $223\left(\mathrm{C}_{12} \mathrm{H}_{1}-\mathrm{NO}_{3}\right)$ & N-Methyl-O-methylty rosine methyl ester \\
\hline & M4 & $237\left(\mathrm{C}_{13} \mathrm{H}_{4} \mathrm{NO}_{3}\right)$ & $\mathrm{N} X$-Dimethy $1-O$-methylty rosine methyl ester \\
\hline \multirow[t]{3}{*}{ Valine } & MI & $131\left(\mathrm{C}_{5} \mathrm{H}_{13} \mathrm{NO}_{2}\right)$ & Valine methyl ester \\
\hline & M2 & $145\left(\mathrm{C}_{2} \mathrm{H}_{1} \leqslant \mathrm{NO}_{2}\right)$ & N-Methylvaline methyl ester \\
\hline & Mi & $159\left(\mathrm{C}_{8} \mathrm{H}_{1} \div \mathrm{NO}_{2}\right)$ & Nin-Dimethylvaline methyl ester \\
\hline
\end{tabular}

direct methylated py rolysis products. Possible direct methylating sites of an amino acid are $\alpha$-carboxylic acid $\left(-\mathrm{CO}_{2} \mathrm{H}\right)$ and $\alpha$-amine (-NH${ }_{2}$ ) of the backbone and side polar groups such as amine carboxylic acid. and hydroxyl groups. Of the direct methy lating sites of the backbone. first the $\alpha$-carboxylic acid group is methylated and then the $\alpha$-amine group will be methylated. If the a-carboxylic acid group is blocked by intramolecular hydrogen bonding, the methylation reaction with the $\alpha$-carboxylic acid group will be unlikely. Since the above six amino acids have polar side chains such as $-\mathrm{CO}_{2} \mathrm{H}$, $-\mathrm{CONH}_{2}-\mathrm{NH}_{\alpha^{+}}=\mathrm{NH}$, or $-\mathrm{SH}$ (Scheme 1), the intramolecular hydrogen bonding with the $\alpha$-carboxylic acid group happens frequently. In addition. the amino acids can be fixed on the

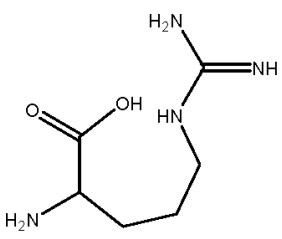

Arginine

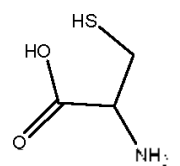

Cysteine<smiles>NC(=O)CC(N)C(=O)O</smiles>

Asparagine<smiles>NC(CCC(=O)O)C(=O)O</smiles>

Glutamic acid<smiles>C=C(O)CC(N)C(=O)O</smiles>

Aspartic acid

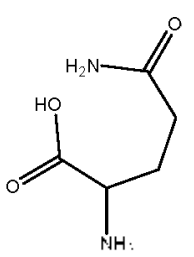

Glutamine
Scheme 1. Structures of amino acids which do not generate any directly methylated products. silica surface by hydrogen bonding with silanol groups. Since silica surface is acidic because of a number of hydroxyl groups (silanol groups) on the surface, which results in adsorption of polar materials by hydrogen bonds. especially it forms a strong hydrogen bond with basic materials. ${ }^{15-2}$ In previous works, ${ }^{8.16}$ the direct methylated products of cysteine. glutanic acid. and glutamine were reported, but these studies used TMAH excess and did not employ silica. Another reason for no direct methylation may have been more favorable other reactions such as cyclization and dissociation processes. Arginine. asparagine, glutamic acid. and glutamine predominantly generated cyclic py roly'sis products through intramolecular cylization reaction by loss of $\mathrm{H}_{2} \mathrm{O}, \mathrm{NH}_{3}$. and other species. The major cyclic pyrolysis products formed from arginine. asparagine. glutamic acid. and glutamine were 1-metlyyl-3-( $N$-methylamino) piperidin-2-one, 1-methỵl-py rrole-2,5-dione, l-methỵl-3-hydro-pyrrole-2-one, and $V$-methyl-5-oxoproline methyl ester, respectively. Aspartic acid and cysteine generated dimerized py rolysis products by loss of $\mathrm{H}_{2} \mathrm{O}$. The major dimerized py rolysis products formed from aspartic acid and cysteine were 3.4-dideliydropy rrolidine-2.5-dione and di(methylthio)methane. respectively.

Ly sine has five direct methylating sites and tri-, tetra-, and pentamethylated species were observed. The tri- and tetramethylated products were found to be two types each as shown in Figure 1 . The peaks at 12.70 and 12.96 min are trimethy lated products assigned to $N^{\prime} . V^{\prime \prime}$-dimethyllycine methyl ester and N. N-dimethylycine methyl ester respectively. while the peaks at 12.89 and $13.38 \mathrm{~min}$ are tetrametlyylated products assigned to $N_{,} N^{\prime} N^{\prime}$-trimethyllycine methyl ester and $N_{,} N_{,} N^{\prime}$-trimethyllycine methyl ester. respectively. Figures 2 and 3 show the mass spectra of the tri- and tetramethylated products. Another 


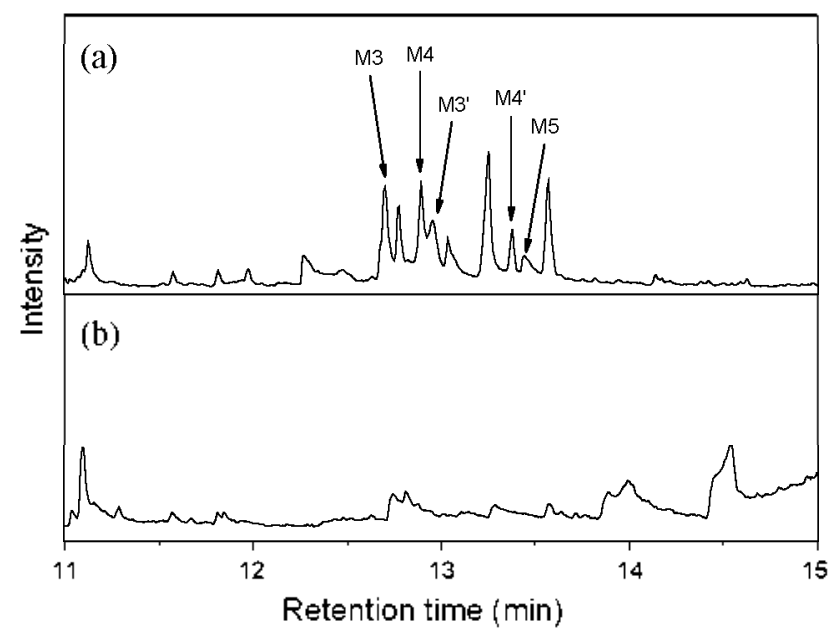

Figure 1. Pyrolysis-GC/MS chromatograms of the lysine/silica ratios of $0.2(\mathrm{a})$ and 2.0 (b) at $700^{\circ} \mathrm{C}$.

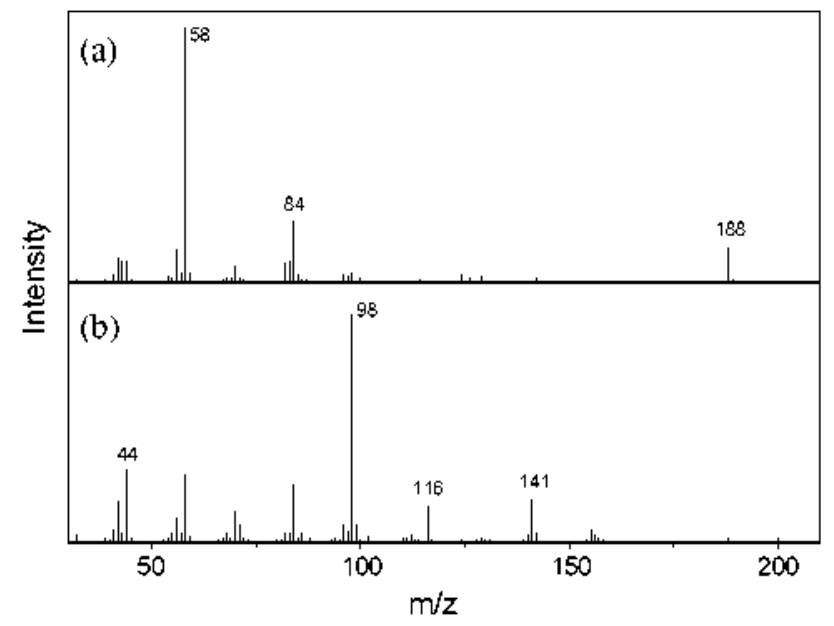

Figure 2. Mass spectra of the trimethylated pyrolysis products M3 (a) and $\mathrm{M} 3^{\circ}$ (b) of ly sine. The $\mathrm{M} 3$ (12.71 min) and $\mathrm{M3} 3^{\prime}$ (12.96 min)

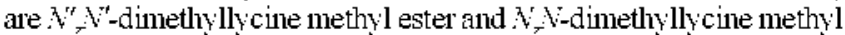
ester, respectively.

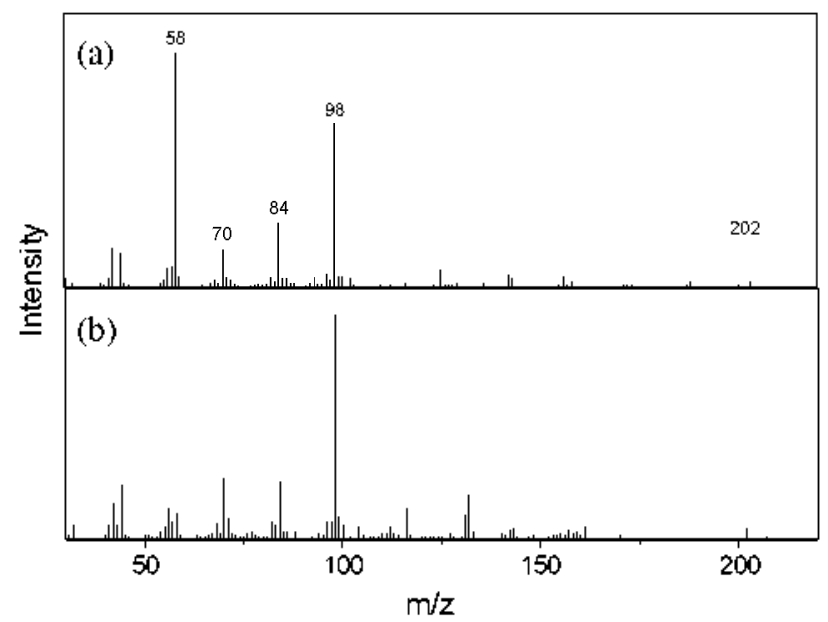

Figure 3. Mass spectra of the tetramethy lated pyroly sis products M4 (a) and $\mathrm{M}_{4}{ }^{*}$ (b) of ly sine. The $\mathrm{M} 4$ ( $12.89 \mathrm{~min}$ ) and $\mathrm{M} 4{ }^{*}$ (13.38 mint) are $N_{r} V^{\prime}, V^{\prime \prime}$-trimethyllycine methyl ester and $N_{r} V_{r} V^{\prime}$-trimethyllycine methyl ester, respectively.

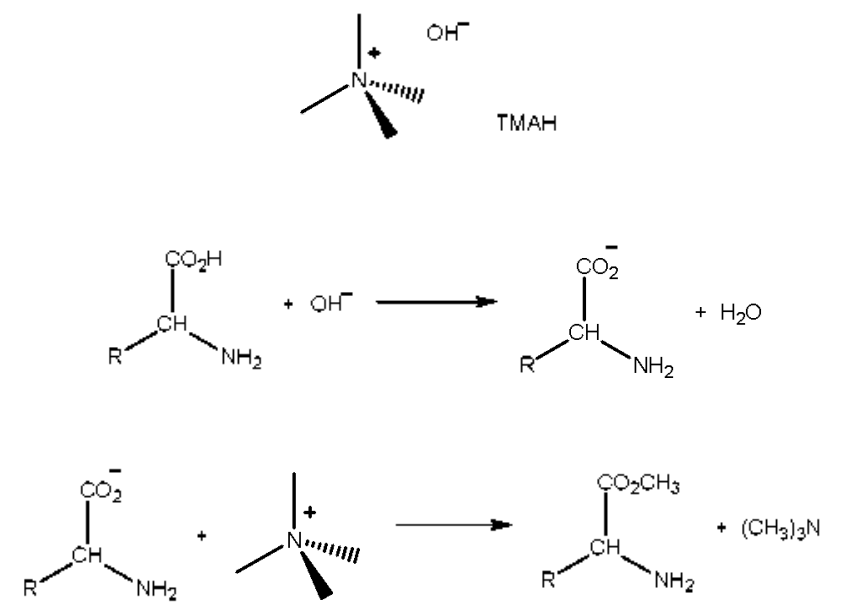

Scheme 2. Direct methylation reaction mechanism of a-carboxylic acid of amino acid with TMAH<smiles>NC(N)C(=O)O</smiles><smiles>NCC(=O)O</smiles><smiles>CCC(C)C(N)C(=O)O</smiles><smiles>CC(C)CC(N)C(=O)O</smiles><smiles>CSCCC(N)C(=O)O</smiles><smiles>NC(Cc1ccccc1)C(=O)O</smiles><smiles>O=C(O)C1CCCN1</smiles><smiles>CC(C)C(N)C(=O)O</smiles>

Scheme 3. Structures of amino acids which generate all the directly methylated products.

possible trimethylated product of lysine is $N_{,}{ }^{\prime}$-dimethylly'cine methyl ester, but this was not observed in this study. All the product ions were identified based on interpretation of the fragment ions and the literature data. ${ }^{8,16}$

Histidine generates only fully methylated product $N . N N^{\prime}-$ trimethylhistidine methyl ester. This implies that the methylation reaction of histidine with TMAH occurs very fast and the equilibrium constant is also very large. The acid dissociation constant $\left(\mathrm{K}_{a}\right)$ of histidine is relatively higher than other amino acids. The $\mathrm{pK}_{\mathrm{a}}$ values of histidine are 1.60 .9 .28 , and 5.97 for $\alpha$-carboxylic acid, $\alpha$-amine, and side group amine. respectively: ${ }^{23}$ The direct methylation reaction requires abstracting a proton from an amino acid by a hydroxide ion of TMAH and then methyl is added to the amino acid as shown in Scheme 2. Thus. anino acids with ligher acid dissociation constants may be more favorable for methylation. For threonine, the fully methylated product was observed but the partly ones were not generated except for the monometlyy lated product (Ml) wluch was observed by trace amount.

Peak intensity ratios of the partly metlyylated products were plotted as a function of the amino acid concentration (amino $\mathrm{acid} / \mathrm{silica}$ ) to investigate the silica effect and the fully methylated product was employed as a reference. Alanine. glycine, isoleucine. leucine. methionine phenylalanine. valine, and proline generated all the methylated pyrolysis products. Their 


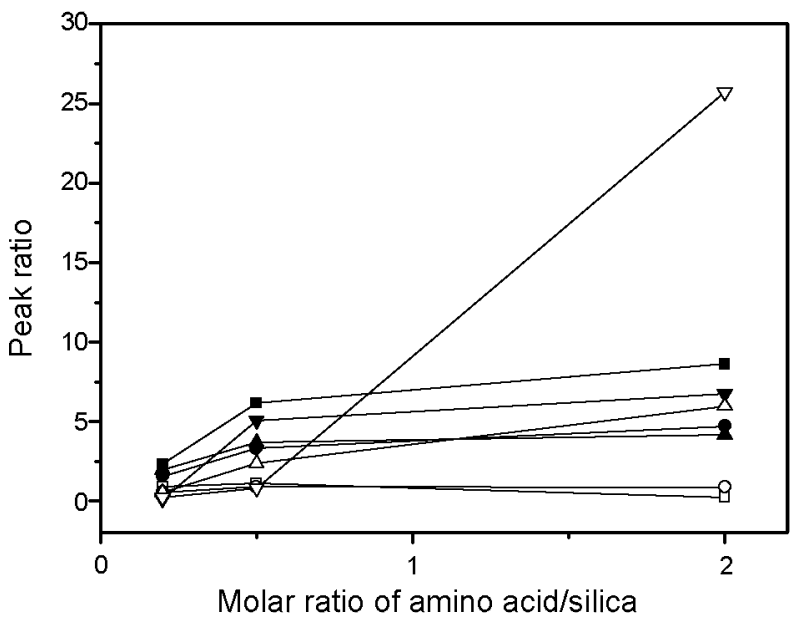

Figure 4. Variation of the methylated product ratios of alanine with the amino acid concentration (amino acid/silica $\left(\mathrm{SiO}_{2}\right)$ by molar ratio). Squares, circles, up-triangles, down-triangles indicate the pyrolysis temperatures of $400,500,700$, and $900^{\circ} \mathrm{C}$, respectively. Solid and open symbols stand for the MI/M3 and M2/M3 ratios, respectively.

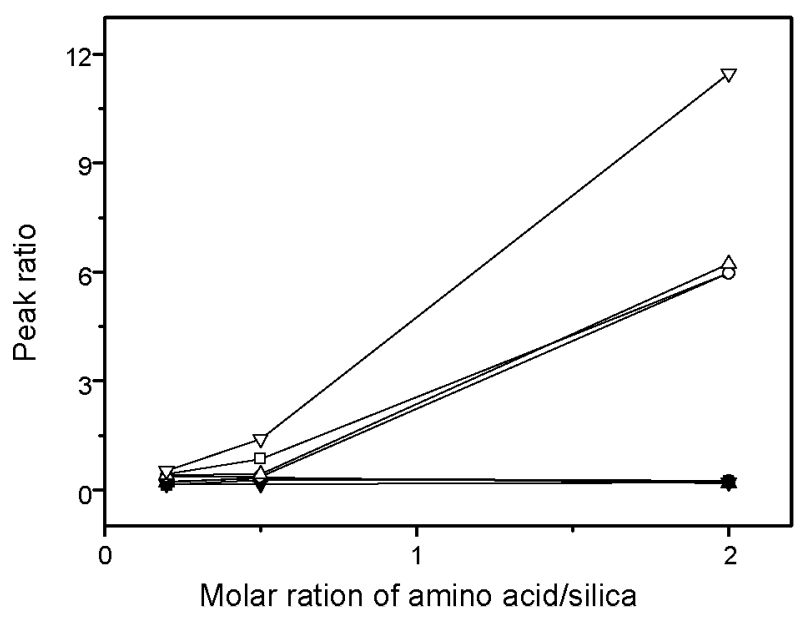

Figure 5. Variation of the methylated product ratios of glycine with the amino acid concentration (amino acid/silica (SiO $)$ by molar ratio). Squares, circles, up-triangles, down-triangles indicate the pyrolysis temperatures of $400,500,700$, and $900^{\circ} \mathrm{C}$, respectively. Solid and open symbols stand for the MI/M3 and M2/M3 ratios, respectively.

common characteristic is that they do not have any side polar groups as shown in Scheme 3. Figures $4-7$ show their peak intensity ratios of the partly methylated products compared to the fully methylated one. For alanine. the monomethylated product (Ml) is more abundant than the fully methylated product (M3) and the difference increases with increasing the amino acid concentration (amino acid/silica) as shown in Figure 4. The dimethylated product (M2) is less abundant than the M3 except under the high py rolysis temperature and high amino acid concentration. The Mi/M3 and $\mathrm{M} 2 / \mathrm{M} 3$ ratios tend to increase with increasing the amino acid concentration except for the $\mathrm{M} 2$ at 400 and $500^{\circ} \mathrm{C}$. The py roly sis temperature effect on the relative abundances did not show a specific trend. but only the $\mathrm{M} 2 / \mathrm{M} 3$ at 2.0 of the amino acid concentration increases

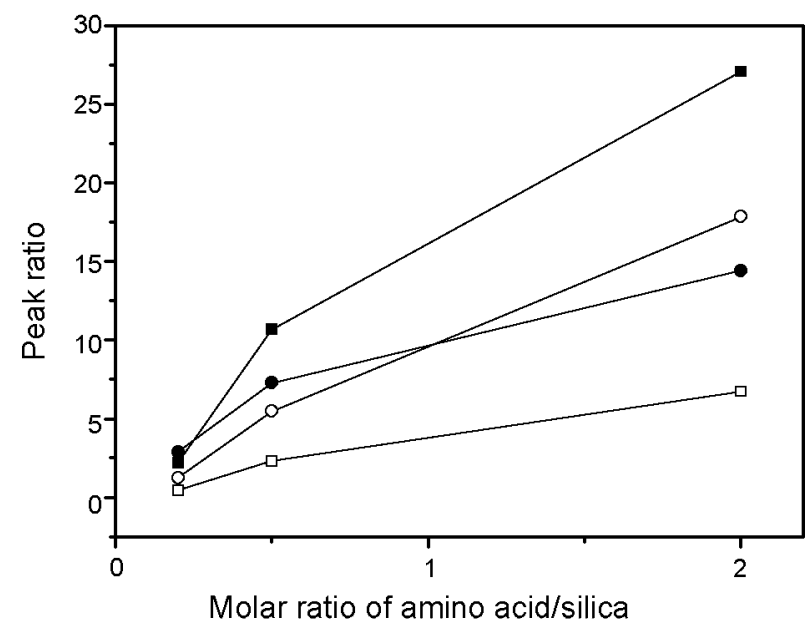

Figure 6. Variation of the methylated product ratios of isoleucine and leucine with the amino acid concentration (amino acid/silica $\left(\mathrm{SiO}_{2}\right.$ ) by molar ratio). The pyrolysis temperature was $5000^{\circ} \mathrm{C}$. Squares and circles indicate the pyroly sis products of isolencine and leucine, respectively. Solid and open symbols stand for the M1/M3 and M2 i M3 ratios, respectively.

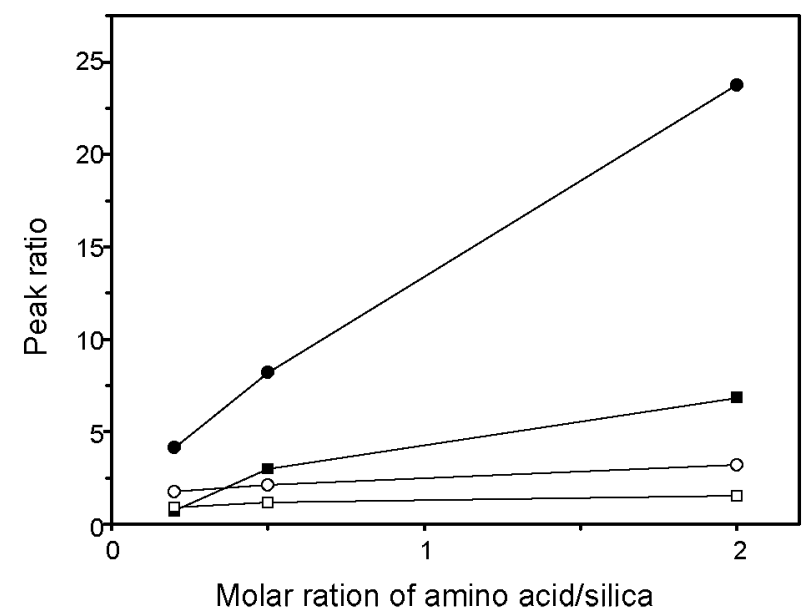

Figure 7. Variation of the methylated product ratios of methionine and phenylalanine with the amino acid concentration (amino acid silica $\left(\mathrm{SiO}_{2}\right)$ by molar ratio ). The pyrolysis temperature was $500^{\circ} \mathrm{C}$. Squares and circles indicate the pyrolysis products of methionine and phenylalanine, respectively. Solid and open symbols stand for the $\mathrm{Ml} / \mathrm{M} 3$ and $\mathrm{M} 2 / \mathrm{M} 3$ ratios, respectively.

with increasing the pyrolysis tenperature. For glycine, only the dimethylated product (M2) at high amino acid concentration of 2.0 is more abundant than the fully methylated product (M3). The M2/M3 ratios increases with increasing the amino acid concentration and the ratio at the amino acid concentration of 2.0 also increases with increasing the py rolysis temperature as shown in Figure 5.

Direct methylation patterns of isoleucine and leucine show similar trends as shown in Figure 6. For isoleucine. the monomethylated product (M1) is more abundant than the dimethylated product (M2) and the partly methylated products are more abundant than the fully methylated product (M3) when the amino acid concentration is high or the py rolysis temperature is low. The partly methylated products increase with increa- 
sing the amino acid concentration. For leucine, the partly methylated products ( $\mathrm{Ml}$ and $\mathrm{M} 2$ ) also tend to increase with increasing the amino acid concentration. The partly methylated products are also greater than the fully methylated product (M3) when the amino acid concentration is high.

For methionine. the monomethylated product (Ml) is greater than the dimethylated product (M2) except for the low amino acid concentration of 0.2 and the partly methylated products are more abundant than the fully methylated product (M3) when the amino acid concentration is high (Figure 7). The Ml/M3 ratios increase with increasing the amino acid concentration. For pheny lalanine, the monomethy lated product (M1) is also more abundant than the dimethylated product (M2) except for the low amino acid concentration of 0.2 and the partly methylated products are more abundant than the fully methylated product (M3) (Figure 7). The M1/M3 ratios increase with increasing the amino acid concentration.

Proline generated generated partly methylated product (M1) and fully methylated product (M2). The M1 is less abundant than the M2 except for the high amino acid concentration of 2.0 at low py roly sis temperatures. For valine. the partly methylated products (M1 and M2) are more abundant than the fully methylated product (M3) when the amino acid concentration is high. Of the eight amino acids. except glycine. the monomethylated products of the seven ammo acids increase with increasing the amino acid concentration. This is because the TMAH concentration is relatively low at the high amino acid concentration. Only for glycine. the monomethylated products are less abundant than the dimethylated ones. This implies that the methylation reaction of the amine group of glycine is very fast after methylation of the carboxylic acid group.<smiles>NC(CO)C(=O)O</smiles>

Serine

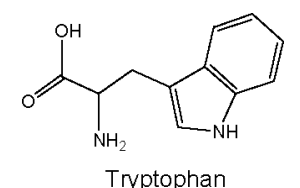

Tryptophan

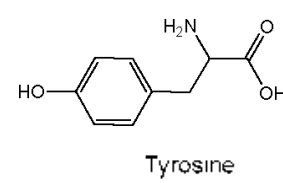

Scheme 4. Structures of amino acids which generate the trimethylated and fully methylated products.

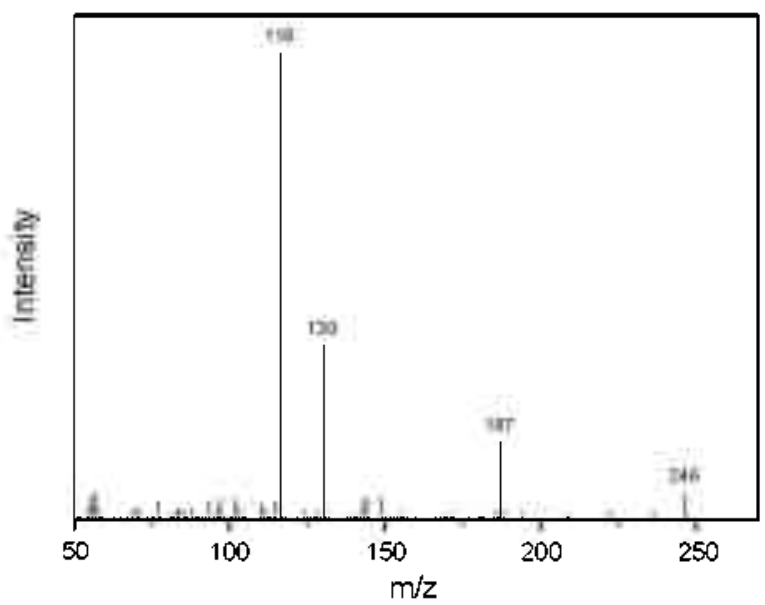

Figure 8. Mass spectrum of the trimethylated pyrolysis product of trptophan. This is assigned to $x_{\text {ind }}$-dimethyl trytophan methyl ester.
Though serine. tryptophan. and tyrosine have four metlyylation sites, they generate only the trimethylated product and the fully methylated product (Mt). They have three methylation groups including $\alpha$-carbosyic acid. $\alpha$-amine, and the side polar group as shown Scheme 4. Serine and tyrosine have a hydrosyl side group and tryptophan has an amine side group. The trimethylated products of serine and ty rosine are $N$-methyl-()-methylserine methyl ester and $N$-methyl-()-methylty rosine methyl ester. respectively. Thus, the order of the methylation is $\alpha$-carboxylic acid $\rightarrow$ hydroxyl $\rightarrow \alpha$-amine. The methylation order is closely related with the acidities of the func-

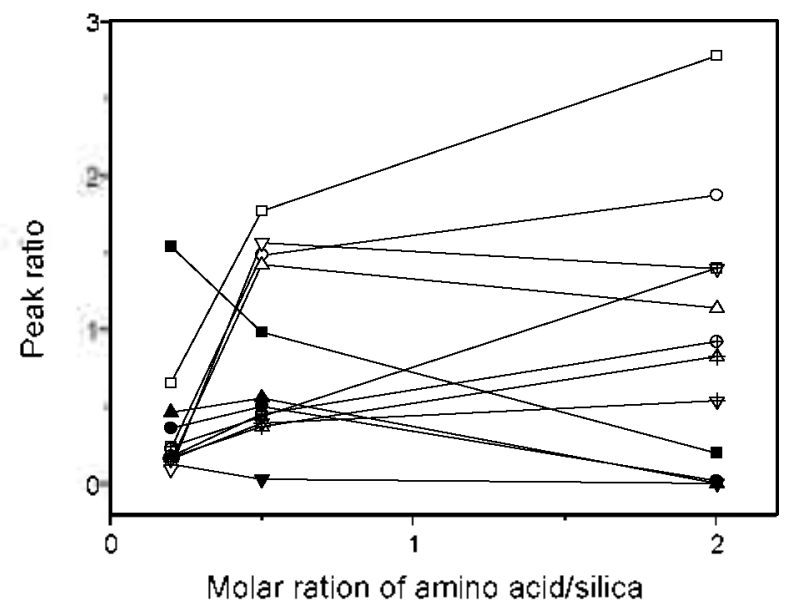

Figure 9. Variation of the methylated product ratios (M3/M4) of serine, tryptophan, and tyrosine with the amino acid concentration (amino acid/silica ( $\mathrm{SiO}_{2}$ ) by molar ratio). Squares, circles, up-triangles, down-triangles indicate the pyrolysis temperatures of 400 , 500,700 , and $900^{\circ} \mathrm{C}$, respectively. Solid, open, and crossed symbols stand for serine, tryptophan, and tyrosine, respectively.

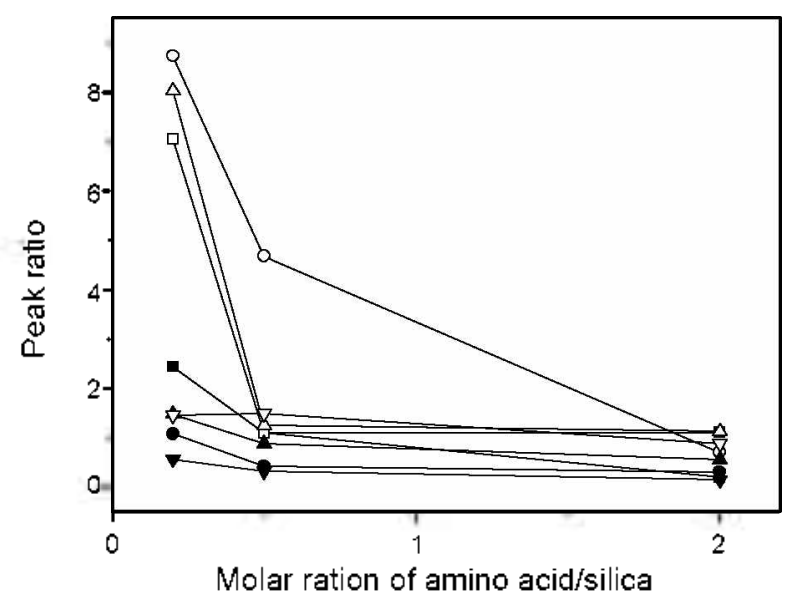

Figure 10. Variation of the methylated product ratios (M3/M5, $\mathrm{M} 3 / \mathrm{M} 5, \mathrm{M} 4 / \mathrm{M} 5$, and $\mathrm{M4} / \mathrm{M} 5$ j of lysine with the amino acid concentration (amino acid/silica $\left(\mathrm{SiO}_{2}\right)$ by molar ratio). Solid and open symbols stand for the pyrolysis temperatures of 500 and $900^{\circ} \mathrm{C}$, respectively. Squares, circles, up-triangles, down-triangles indicate the pyrolysis product ratios of $\mathrm{M} 3 / \mathrm{M} 5, \mathrm{M} 3 / \mathrm{M} 5, \mathrm{M} 4 / \mathrm{M} 5$, and $\mathrm{M}^{\prime} / \mathrm{M} 5$, respectively. The M3, M3', M4, and M4' are $\mathrm{I}^{\prime \prime}, \mathrm{N}^{\prime}$ dimethyllycine methyl ester, $\mathrm{H}$-dimethyllycine methyl ester, $X N N^{\prime}$-trimethyllycine methyl ester, and $A, N$-trimethyllycine methyl ester, respectively. 
tional groups. The trimethylated product of tryptophan is $N . X$. dimethỵltryptophan methỵl ester. but Gallois and coworkers ${ }^{16}$ reported that it was $\mathrm{N}^{\prime}$-methyl-1-methyltryptophan methyl ester. Principal ions (and the relative ion intensities) in the mass spectrum of the trimethylated product of tryptophan are $m / z 116(100 \%), 130(37 \%) .187(17 \%)$, and $246(6 \%)$ as shown in Figure 8 . The $m / z 246$ is the molecular ion and the $m / z 116,130.187$ are the fragment ions assigned to $\mathrm{CH}_{3} \mathrm{O}_{2}$ $\mathrm{CCH}=\mathrm{N}\left(\mathrm{CH}_{3}\right)_{2}^{-},\left[\mathrm{M}-\mathrm{CH}_{3} \mathrm{O}_{2} \mathrm{CCH}-\mathrm{N}\left(\mathrm{CH}_{3}\right)_{2}\right]^{-}$, and $\left[\mathrm{M}-\mathrm{CO}_{2}\right.$ $\left.\mathrm{CH}_{3}\right]^{-}$. respectively. Thus the trimethylated product of tryptophan is $N$, $N$-dimethyltryptophan methyl ester not $N^{\prime \prime}$-methyl- $N$ methỵltryptophan methỵl ester. Figure 9 shows the peak intensity ratios of the $\mathrm{M} 3 \mathrm{M}+$ of serine, tryptophan and ty rosine with the amino acid concentration. Only for tryptophan. the trimethylated product is more abundant than the fully methylated product $(\mathrm{M}+)$ when the amino acid concentrations are ligh of 0.5 and 2.0 . The $\mathrm{M} 2 / \mathrm{M} 3$ ratios of serine decrease with increasing the amino acid concentration whereas those of tyrosine increase. Variations of the $\mathrm{M} 2 / \mathrm{M} 3$ ratios with the pyroly sis temperature do not show clear trends, but the ratios tend to increase with increasing the pyrolysis temperature.

Tri- and tetramethylated products of ly sine consisted of two types as discussed previously. Figure 10 shows the peak intensity ratios of the M3 (or M3 ')/M5 and M4 (or M4)/M5 as a function of the amino acid concentration. The M3 (or M3')/M5 and $\mathrm{M} 4$ (or $\mathrm{M} 4^{\circ}$ )/M5 ratios tend to decrease with increasing the amino acid concentration. This implies that formation of the tri- and tetramethy lated products of lysine requires excess TMAH. At the low amino acid concentration of 0.2 . the partly methylated products tend to increase with increasing the pyrolysis temperature. This implies that formation of the partly methy lated products requires high energy. Thus. formation of the partly methylated products of lysine is dependent on high TMAH concentration and high energy. Consistent trends for the intensity ratios between the isomers of $\mathrm{M} 3 / \mathrm{M} 3$ ' and $\mathrm{M} 4 /$ M4' were not found. For high yield conditions at high pyrolysis temperature and low amino acid concentration the M3" (N.N-dimethyllycine methyl ester) is more abundant than the M3 ( ${ }^{\prime}, N^{\prime}$-dimethyllycine methyl ester) whereas the Mt* (N.). ${ }^{\prime}$-trimethyllycine methyl ester) is less abundant than the M4 ( $N, N^{\prime} N^{\prime}$-trimethỵllỵ cine methỵl ester).

\section{Conclusions}

Arginine asparagine, aspartic acid cy steine glutamic acid. and glutamine did not generate any directly methylated products. whereas alanine glycine. isoleucine. leucine. methionine. phenylanaline, valine. and proline produced all the directly methylated products. The non-producing amino acids have structures composed of intramolecular hydrogen bonding while the others do not have any side functional groups such as amine, alcohol or carboxy lic acid. Ly sine generated two trimethylated products $\left(N^{\prime} . Y^{\prime}\right.$-dimethyllycine methyl ester and $N$ N-dimethyllycine methyl ester) and two tetramethy lated products $\left(N . N^{\prime} . N^{\prime}\right.$ trimethyllycine methyl ester and $N . X . V^{\prime \prime}$-trimethỵlly cine methỵl ester). High TMAH concentration and lighenergy were required to form partly methylated products of lysine. Histidine and threonine mainly generated only the fully methylated products. Even though serine. tryptophan, and ty rosine have four methylation sites. they generated only the trimethylated product and the fully methylated product (M4).

\section{Refelences}

1. Moldoveanu, S. C. Analvical Pwolysis of Ratumal Orgonic Pohmers Techniques and Instrumentation in. Anahtical Chemistry, Vol. 20: Elsevier: Ansterdam, 1998.

2. Schulten, H. R.; Gleivner, G. Water Res. 1999, 33, 2489-2498

3. Koo, J.: Park, C. H.; Han, C.; Na, Y. C. Bull. Kor Chem. Soc. $2009,30,368-372$

4. Ratcliff, M. A:; Medley, E. E; Simmonds, P. G. J. Org. Chem. 1974, 39, 1481-1490.

5. Chiavari, G:; Galletti, G. C. J. Anal Appl. Pyrolysis 1992, 24 , 123-137.

6. Stankiewicz, B. A.; van Bergen, P. F.: Duncan, I. J.: Carter, I. F.; Briggs, D. E. G.; Evershed, R. P. Rapid Commun. Hass Spectront. $1996,10,1747-1757$.

7. Basiuk, V. A.; Navano-Gonzalez, R; Basink, E. V. J. Anal. Appl. Pyrolvis $1998,45,89-102$.

8. Zang, X.: Brown, I. C.: van Heemst, J. D. H.: Palumbo, A.; Hatcheret, P. G. J. Anal. Appl Pyrolysis 2001, 61, 181-193.

9. Challinor, J. M. J. Anat Appl Pyrolysis 1989, 16, 323-333.

10. Lehtonen, T.: Pelıavuori, J.: Pihlaja, K. J. Anal. Appl Pyrolusis 2003, 68:69, 315-329

11. Joll, C. A.: Huyn, T:; Heitzet, A. J. Anal. Appl. Prolysis 2003, $70,151-167$

12. Voorhees, K. J.; Basile, F.; Beverly, M. B.; Abbas-Hawks, C.; Hendricker, A.; Cody, R. B.; Hadfield, T. L. I. Anal Appl. Pyolysis 1997, $40+11,111-134$.

13. Abbas-Hawks, C.; Voorhees K. T.; Hadfield, T. L. Rapid Commun. Mass Spectrom. 1996, 10, 1802-1806.

14. Zang, X.; van Heemst, J. D. H.: Dna, K. T.; Hatcher, P. G. Org. Geochent 2000,31, 679-695.

15. Knicker, H.; Hatcher, P. G. Natumissenschoften 1997, 84, $231-234$

16. Gallois, N.; Templier, T.; Derente, S. I. Anal. Appl. Pwolysis 2007, $80,216-230$

17. Hendricker, A. D.: Voorhees, K. I. J. Anal .Appl Pyrolysis 1998. $48,17-33$

18. Kuroda, K; Inoule, Y; Sakai, K. J. Anal. Appl Pyolysis 1990, 18, 59-69.

19. Wolff, S.; Wang, M.-J. Rubber Chent. Technol. 1992, 65, 329.

20. Ou, Y.C.: Yul, Z.-Z.: Vidal, A.: Donnet, I. B. Rubber Chem. Techol $1994,67,834$.

21. Byers, T. T. Rubber Wontd 1998, 218(6), 38.

22. Choi, S.-S.: Choi, S.-I. Bull. Kor: Chem. Soc. 2006, 27, 1473.

23. Nist standard reference database number 69 , http://webbook. nist.gov/chemistry/. 